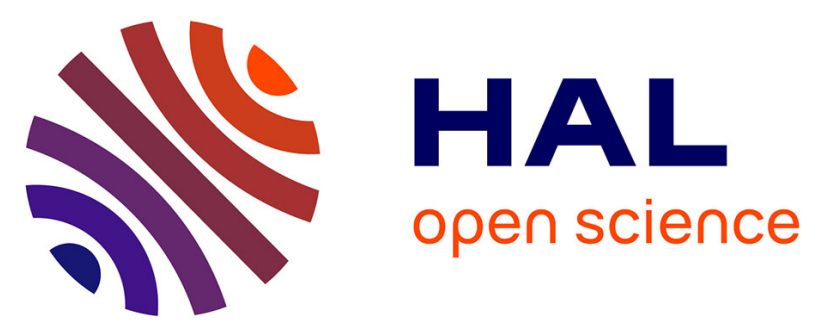

\title{
Involvement of first-time mothers with different levels of education in the decision-making for their delivery by a planned Caesarean section. Women's satisfaction with information given by gynaecologists and midwives
}

Petra Kolip, Roland Büchter

\section{To cite this version:}

Petra Kolip, Roland Büchter. Involvement of first-time mothers with different levels of education in the decision-making for their delivery by a planned Caesarean section. Women's satisfaction with information given by gynaecologists and midwives. Journal of Public Health, 2009, 17 (4), pp.273-280. 10.1007/s10389-008-0246-1 . hal-00535273

\author{
HAL Id: hal-00535273 \\ https://hal.science/hal-00535273
}

Submitted on 11 Nov 2010

HAL is a multi-disciplinary open access archive for the deposit and dissemination of scientific research documents, whether they are published or not. The documents may come from teaching and research institutions in France or abroad, or from public or private research centers.
L'archive ouverte pluridisciplinaire HAL, est destinée au dépôt et à la diffusion de documents scientifiques de niveau recherche, publiés ou non, émanant des établissements d'enseignement et de recherche français ou étrangers, des laboratoires publics ou privés. 


\title{
Involvement of first-time mothers with different levels of education in the decision-making for their delivery by a planned Caesarean section. Women's satisfaction with information given by gynaecologists and midwives
}

\author{
Petra Kolip • Roland Büchter
}

Received: 4 August 2008 / Accepted: 3 December 2008 / Published online: 13 January 2009

(C) Springer-Verlag 2009

\begin{abstract}
Aims We investigated the involvement of first-time mothers, who had a planned Caesarean section, in the decision to have a Caesarean section, taking into account their different educational levels.

Subjects and methods A self-assessment questionnaire was sent in July 2005 to women who had undergone a Caesarean section in 2004. Participants were 2,685 members of a statutory health insurance fund who had given birth by Caesarean section (response rate: $48.0 \%$ ). Included were primiparae with planned Caesarean section $(n=352)$. Results The women in this cross-sectional study felt well informed about the procedure of a section but not its consequences. They used several sources of information and were most satisfied with the information provided by doctors and midwives. Of the women in this study $20 \%$ did not have a midwife. No major differences were observed between different educational levels.

Conclusion Although most women were satisfied with their decision, they felt that they did not receive enough information about the consequences of a Caesarean section. This information need could be met by a further involvement of midwives in maternity care.
\end{abstract}

Keywords Caesarean section - Shared decision-making . Information needs $\cdot$ Birth

P. Kolip $(\bowtie) \cdot$ R. Büchter

Universität Bremen, Institut für Public Health und Pflegeforschung,

Grazer Str. 4,

28359 Bremen, Germany

e-mail: kolip@uni-bremen.de

\section{Introduction}

Similar to other developed nations (Denk et al. 2006), there has been a steady rise of Caesarean sections in Germany in recent years: in 2006, the rate was $28.6 \%$ compared to 15.7\% in 1990 (OECD Health Data 2006). From the public health point of view, planned Caesarean sections, where the decision to perform a section is reached before labour (as opposed to intrapartum or emergency sections), have recently come under particular scrutiny. In Germany, planned Caesarean sections remain at a constant $50 \%$ of all section births (BQS 2008). Although the risks of a Caesarean section have been considerably reduced due to improved surgical and anaesthetic technologies as well as infection prophylaxis drug treatment, the morbidity/mortality rate is still higher than for vaginal birth (Menacker et al. 2006; NICE 2004; Liu et al. 2007; Enkin et al. 2000). Therefore, women should have the opportunity to be involved in the decision regarding the mode of delivery as is suggested by shared decision-making concepts (Scheibler et al. 2003; Charles et al. 1999). The risks of Caesarean section require careful consideration and should be adequately explained to expectant mothers (McFarlin 2004; Leslie 2004; American College of Obstetricians and Gynecologists 2004), in particular when dealing with a planned Caesarean section with a relative indication (e.g. breech presentation). Against this backdrop, we need to consider how women are involved in the decision to have a Cesarean section.

As studies from the USA and UK show, many women feel that they do not receive sufficient information from maternity caregivers to enable them to participate in childbirth decisions (Turnbull et al. 1999; Fleissig 1995), even though women who are involved in the decision to 
have an elective Caesarean section appear to be significantly happier than those women who feel they have not been involved (Graham et al. 1999). In Germany, women are usually kept informed by their local gynaecologists, midwives who take care of them during the pregnancy and, to a lesser degree, doctors and midwives in hospital. Women in Germany can choose to receive their maternity care during pregnancy from a gynaecologist, a midwife, or a combination of both.

If women are to be involved in the decision to have a Caesarean section, it is necessary to give them not only sufficient information about the short-, medium- and long-term risks and benefits of such an intervention, but also to provide details of the operation itself (e.g. type of anaesthesia) (Horey et al. 2004). It is also relevant to consider whether differences in levels of education need to be taken into account. Interestingly, hardly any studies have been carried out on the information requirements of pregnant women with regard to methods of childbirth (Horey et al. 2004) - and even fewer studies have analysed these information requirements in the context of a Caesarean section and according to different levels of education. This is surprising since less educated woman are more likely to have a Caesarean section (Tollånes et al. 2007). In a qualitative study, Stapleton et al. (2002) showed that pregnant women normally follow the advice of their gynaecologist, who usually fails to adequately inform them about the risks of a technical intervention. In a retrospective study (Mould et al. 1996), 51.7\% (15 of 29) of women who had undergone an elective Caesarean section felt that they had made a significant or full contribution towards the decision, and $31.0 \%$ were of the opinion that they had made only a small contribution or none at all. Turnbull et al. (1999) reported that $81.4 \%$ of women who had undergone an elective Caesarean section felt that they had been involved in the decision-making. Just over half of the women questioned in this study (50.4\%, with no distinction made between a planned or intrapartum section) were happy with their decision in retrospect, and $62.3 \%$ were sure that they had made the right decision.

Differences in levels of education are rarely investigated. However, they appear to be small (Freda et al. 1993) or point to the fact that, compared to non-manual workers, women who are manual workers are more likely to feel that they have been able to make informed decisions within the context of maternity care (O'Cathain et al. 2002).

The present study uses an explorative approach and focuses retrospectively on the involvement of primiparae (women who give birth to a child for the first time) in the decision to have a planned Caesarean section. The study surveyed women who had given birth by Caesarean section in the previous 12 months. We were interested in answers to the following questions:

- Were the women satisfied with the information given by midwives and gynaecologists about the procedures and consequences of a Caesarean section?

- Which sources of information did the women use?

- Are there any differences that may be explained by different levels of education?

\section{Methods}

Sample

The work presented is part of a larger study focusing on the experiences of women who have had a planned or intrapartum Caesarean section (Lutz and Kolip 2006). The study included all women from the Gmünder Ersatzkasse statutory health insurance fund who had undergone a Caesarean section in $2004(n=2,685)$. The women were identified in the Administration Centre by means of the master data record and OPS code (Operation and Procedure Code) and in July 2005 were sent an anonymous questionnaire by the health insurance fund. A stamped addressed envelope was enclosed for return of the form to the research team. The response rate was $48.0 \%(n=1,339)$. As it was not possible to send a reminder, any questions regarding non-responders remain unanswered. Participation in the study was voluntary.

For this part of the study, we selected primiparae who had undergone a planned Caesarean section $(n=352 ; 26.3 \%$ of the total sample; $45.5 \%$ of all planned sections).

\section{Questionnaire}

In the process of developing the questionnaire, gynaecologists and midwives were involved to deal with a variety of aspects relevant to the study (Lutz and Kolip 2006):

- Reasons for the Cesarean section: The reasons that led to the Cesarean section were assessed via a list of 24 possible reasons. Women were asked to indicate the importance of each reason (ranging from $1=$ was a very important reason to $4=$ wasn't important at all).

- Level of education/school qualifications: secondary school leaving certificate (Hauptschulabschluss), technical school leaving certificate (Realschulabschluss), A level equivalent (Abitur) or higher.

- Information received from the doctor and/or midwife during maternity care about the process and consequences of the Caesarean section: "How good was the information you received on the process/consequences of the Caesarean section?": very good, good, average 
and bad (in the case of midwife, also: "I did not have a midwife"). In the form on an open-ended question we asked whether there was a need for information that had not been satisfied.

- The women's level of satisfaction with their decision was recorded by asking them whether they would have a Caesarean section again under the same circumstances ("yes, definitely", "yes, probably" and "probably not").

- Use of different sources of information: 12 sources of information were specified (e.g. gynaecologist, female relative, Internet); we asked (a) how often these were used ("often/sometimes/seldom/never") and (b) how satisfied they were with the information received. This was assessed using school grades, with 1 as the highest and 6 as the worst grade.

To illustrate some results and to gain a deeper insight into the women's underlying experiences, we made use of some responses to an open-ended question at the end of the questionnaire: "Do you want to make any comments?" Many women used this opportunity to write about their experiences and their attitudes towards Caesarean section.

\section{Data analysis}

Data were analysed using SPSS 12.0. We compared mothers of different educational level using chi-square tests (three groups; see below). We used analysis of variance (ANOVA) to analyse the differences in satisfaction with different sources of information.

\section{Results}

\section{Description of sample}

Of the women questioned, $10.8 \%$ had a secondary school leaving certificate (Hauptschulabschluss), 49.7\% had a technical school leaving certificate (Realschulabschluss), $23.0 \%$ had completed the equivalent of A levels (Abitur) and $11.4 \%$ had a university degree. The latter two groups were categorized together for the purpose of this analysis. Two groups were excluded from the comparisons: $1.7 \%$ had a different educational qualification and $3.4 \%$ failed to answer the question regarding their qualifications.

The majority of births (92.3\%) were single births, $7.4 \%$ were twins and $0.3 \%$ were triplets.

Recommendation of the gynaecologist was the most important reason, followed by malpresentation and the fear that the child may be damaged (see Table 1). Convenience factors, i.e. planning the date, partner's request or a quick birth, were not indicated as important reasons. In an attempt to identify maternal request Caesarean sections we filtered those women giving at least one convenience reason as important or very important (reasons 11, 16, 19 or 21 in the table) and indicating all medical reasons as not important (reasons $2,4,5,6,9,13,15$ or 18). We identified 6 of 352 mothers (1.7\%) who can be assumed as having had a Caesarean section on maternal request.

Information received from midwives and doctors

The results show that the women felt they were better informed about the process of Caesarean section than its consequences. Greater importance was attached to information received from the doctor than that received from the midwife looking after the women during pregnancy (see Table 2). Half of the women questioned (50.8\%) said that the doctor had given them a substantial amount of good information about the process of a Caesarean section, and $25.9 \%$ said the same about their midwife. As far as the consequences of a Caesarean section were concerned, 37.7\% felt their doctor had kept them well informed, and $20.4 \%$ felt the same about their midwife. One in five women $(19.0 \%)$ said that their maternity care had not included a midwife. It was only with regard to information received from the doctor about the Caesarean section process that there were any significant differences according to levels of education. Less educated women felt they had been better informed than those who were better educated. While $59.5 \%$ of those with a secondary school education said that the level of information they had received was very good $(32.4 \%$ "good"), only $48.7 \%$ of those leaving education with the equivalent of A levels felt the same (30.3\% "good") $\left(\chi^{2}=\right.$ 12.85, Cramer's V=.19, $p \leq .05)$. A similar trend not reaching significance was observed with regard to information received from midwives: $36.4 \%$ of those with a secondary school education, but only $22.9 \%$ of those with the equivalent of A levels felt that the information they had received about the section process was very good (18.2/ $22.0 \%$ "good"; $p=.083$ ).

These results tend to be supported by the answers to an open question regarding the need for information that was not satisfied: $10.4 \%$ of the women with the highest qualification, but only $6.1 \%$ of the women with the lowest qualification had questions concerning Caesarean section that went unanswered or who did not know to whom to address the questions in the first place (women with secondary school leaving certificate: $6.6 \%$ ). No significant differences between women with different levels of education were observed.

The results show that women are largely satisfied with the decision they have made: $62.3 \%$ would definitely make the same decision again under similar circumstances, $30.7 \%$ would probably elect to give birth by Caesarean section again and $7.1 \%$ would probably not elect to have a further 
Table 1 Reasons leading to Cesarean section ( $n=352$; missing answers between 36 and $61^{\mathrm{a}}$ )

\begin{tabular}{|c|c|c|c|c|}
\hline & $\begin{array}{l}\text { Very important } \\
\text { reason }\end{array}$ & $\begin{array}{l}\text { Important } \\
\text { reason }\end{array}$ & $\begin{array}{l}\text { Minor important } \\
\text { reason }\end{array}$ & $\begin{array}{l}\text { Wasn't important at } \\
\text { all }\end{array}$ \\
\hline 1. Recommendation by physician & 44.6 & 15.6 & 9.9 & 18.5 \\
\hline 2. Malpresentation (e.g. breech presentation) & 44.3 & 4.8 & 2.8 & 37.8 \\
\hline 3. Fear child may be damaged & 33.0 & 7.4 & 8. 0 & 39.2 \\
\hline 4. Pregnancy complication (e.g. gestosis, preterm) & 27.8 & 2.6 & 2.6 & 53.4 \\
\hline 5. Fetal macrosomia & 14.5 & 4.5 & 4. 8 & 61.4 \\
\hline 6. Mother's disease & 9.9 & 1.4 & 2.6 & 69.9 \\
\hline 7. Recommendation by midwife & 8.2 & 5.1 & 3. 4 & 66.8 \\
\hline 8. Induction of labour failed & 6.5 & 0.6 & 0.6 & 76.1 \\
\hline 9. Twins/triplets & 6.2 & 0.6 & 0.9 & 75.9 \\
\hline 10. Fear of labour pain & 5.4 & 2. 6 & 11.6 & 64.2 \\
\hline 11. Quick birth & 4.0 & 4.3 & 4.3 & 70.2 \\
\hline 12. Imagination of labour as appalling & 4.0 & 3. 4 & 8.5 & 68.8 \\
\hline 13. Post maturity & 4.0 & 2. 0 & 1. 4 & 77.3 \\
\hline 14. Fear of not standing vaginal birth & 3.7 & 4. 0 & 8.0 & 68.5 \\
\hline 15. Fetus's disease & 2. 8 & 0.0 & 0.9 & 80.1 \\
\hline 16. Planning (e.g. date of birth) & 2.6 & 2. 0 & 4. 8 & 74. 1 \\
\hline 17. Fear of physical impairment (e.g. incontinence) & 2. 3 & 2. 0 & 5. 7 & 73. 3 \\
\hline 18. Vaginal infection & 2. 0 & 1. 4 & 1. 1 & 78.7 \\
\hline 19. Partner's request & 1. 4 & 2. 0 & 4.5 & 76.1 \\
\hline 20. Age of mother (too old) & 1. 1 & 0.3 & 1. 7 & 80.4 \\
\hline 21. Expected postnatal sexual impairment & 0.9 & 0.9 & 2. 8 & 79.5 \\
\hline 22. Recommendation by a friend & 0.6 & 0.3 & 5. 1 & 78.7 \\
\hline 23. Lack of attendance by a confident & 0.3 & 0.9 & 1.4 & 81.8 \\
\hline 24. No confidence in midwife or gynaecologist & 0.3 & 0.6 & 3.7 & 79.3 \\
\hline
\end{tabular}

a As a detailed analysis shows most of the missing answers can be interpreted as "wasn't important at all"

Caesarean section. No differences could be detected according to levels of education.

\section{Sources of information}

The most important source of information was the gynaecologist responsible for the women's maternity care (see Table 3). More than two thirds of the women (69.9\%) said that they had frequently used their doctor as a source of information. They also frequently used books $(51.1 \%$ for frequent use) and the midwife providing maternity care $(50.2 \%)$. Other sources of information cited as being seldom used were: videos and DVDs $(0.3 \%$ for frequent use), health insurance funds ( $7.6 \%$ for frequent use) and television (11.2\% for frequent use). The Internet was used by $16.4 \%$ of the respondents. We did not discover any differences according to levels of education for any of the sources of information.

The highest grades for satisfaction were given to the two groups providing the women with professional maternity care. Doctors were given an average grade of 2.02 and midwives an average grade of 2.01. In third place were books, with a grade of 2.18 . The lowest grades were given to videos/DVDs (4.03) and television programmes
(3.11). Information on the Internet was given a grade of 2.54. For the latter there was a significant difference according to levels of education (ANOVA; $F=5.218$; $p=.006$ ): Women with A level equivalent qualifications (Abitur) were considerably more satisfied with information on the Internet (grade 2.09) than either women with a technical school leaving certificate (Realschulabschluss) (grade 2.19) or women with a secondary school leaving certificate (Hauptschulabschluss) (grade 2.49).

\section{Discussion}

Our study suggests that the information requirements of pregnant women in Germany concerning different modes of delivery are largely satisfied. More than $80 \%$ felt they had received a good level of information from their doctor regarding the process and more than $60 \%$ regarding the consequences of a Caesarean section. The findings correspond with other studies, e.g. that of Graham et al. (1999), who were able to demonstrate that $71 \%$ of women who had undergone elective Caesarean sections judged the information they had received about Caesarean section during their pregnancy to be adequate. Two aspects of our findings are 
Table 2 Assessment of the information provided by doctors/midwives on the process and consequences of a Caesarean section according to level of education (without any other qualifications or without qualifications $n=327$; missing answers between 7 and 40 )

\begin{tabular}{|c|c|c|c|c|}
\hline $\begin{array}{l}\text { Level of information on } \\
\text { process ... }\end{array}$ & $\begin{array}{l}\text { Secondary school leaving } \\
\text { certificate (Hauptschulabschluss) }\end{array}$ & $\begin{array}{l}\text { Technical school leaving } \\
\text { certificate (Realschulabschluss) }\end{array}$ & $\begin{array}{l}\text { A level equivalent } \\
\text { (Abitur) or higher }\end{array}$ & Total \\
\hline \multicolumn{5}{|l|}{... provided by the doctor } \\
\hline - Very good & 59.5 & 50.3 & 48.7 & 50.8 \\
\hline - Good & 32.4 & 36.8 & 30.3 & 33.9 \\
\hline - Average & 0.0 & 6.4 & 16.0 & 9.2 \\
\hline • Poor & $\begin{array}{l}8.1 \\
\chi^{2}=12.85, \text { Cramer's } \\
V=.19, p \leq .05\end{array}$ & 6.4 & 5.0 & 6.1 \\
\hline \multicolumn{5}{|l|}{$\ldots$ provided by the midwife } \\
\hline - Very good & 36.4 & 25.8 & 22.9 & 25.9 \\
\hline - Good & 18.2 & 27.2 & 22.0 & 24.2 \\
\hline - Average & 30.3 & 16.6 & 20.2 & 19.5 \\
\hline - Poor & 0.0 & 7.9 & 15.6 & 9.9 \\
\hline - I did not have a midwife & $\begin{array}{l}15.2 \\
\chi^{2}=13.96, \text { Cramer's } \\
\mathrm{V}=.21, p \leq .10\end{array}$ & 22.5 & 19.3 & 20.5 \\
\hline \multicolumn{5}{|c|}{$\begin{array}{l}\text { Level of information on consequences ... } \\
\ldots \text { provided by the doctor }\end{array}$} \\
\hline - Very good & 44.4 & 40.5 & 31.7 & 37.7 \\
\hline - Good & 36.1 & 31.0 & 28.3 & 30.6 \\
\hline - Average & 5.6 & 19.0 & 26.7 & 20.4 \\
\hline • Poor & $\begin{array}{l}13.9 \\
\chi^{2}=9.97, \text { Cramer's } \\
V=.17 \text {, n.s. }\end{array}$ & 9.5 & 13.3 & 11.4 \\
\hline \multicolumn{5}{|l|}{... provided by the midwife } \\
\hline - Very good & 27.3 & 21.6 & 16.7 & 20.4 \\
\hline - Good & 21.2 & 26.8 & 25.0 & 25.5 \\
\hline - Average & 21.2 & 18.3 & 20.4 & 19.4 \\
\hline - Poor & 18.2 & 11.1 & 21.3 & 15.6 \\
\hline - I did not have a midwife & $\begin{array}{l}12.1 \\
\chi^{2}=8.47, \text { Cramer's } \\
V=.17 \text {, n.s. }\end{array}$ & 22.2 & 16.7 & 19.0 \\
\hline
\end{tabular}

Table 3 Frequency of use of different sources of information and satisfaction with the information

\begin{tabular}{|c|c|c|c|c|c|}
\hline & Frequent & Sometimes & Seldom & Never & Satisfaction ${ }^{\mathrm{a}}$ \\
\hline Doctor(s) providing maternity care & 69.9 & 19.3 & 8.4 & 2.4 & 2.02 \\
\hline Clinician & 26.9 & 28.5 & 31.9 & 12.7 & 2.20 \\
\hline Midwife providing maternity care & 50.2 & 22.9 & 11.0 & 15.9 & 2.01 \\
\hline Midwife in the clinic & 20.7 & 21.4 & 22.9 & 35.0 & 2.30 \\
\hline Mother/female relative & 27.5 & 38.1 & 19.9 & 14.5 & 2.42 \\
\hline Friends and colleagues & 24.5 & 36.1 & 17.9 & 21.5 & 2.42 \\
\hline Books & 51.1 & 27.0 & 13.8 & 8.1 & 2.18 \\
\hline Television & 11.2 & 24.0 & 32.8 & 31.9 & 3.11 \\
\hline Newspapers/magazines & 30.2 & 31.7 & 22.4 & 15.7 & 2.44 \\
\hline Video/DVD & 0.3 & 1.5 & 10.3 & 87.8 & 4.03 \\
\hline Internet & 16.4 & 20.1 & 13.4 & 50.2 & 2.54 \\
\hline Health insurance fund & 7.6 & 29.0 & 22.3 & 41.2 & 2.26 \\
\hline
\end{tabular}

${ }^{\text {a }}$ Satisfaction in school grades: 1 = Very good through to $6=$ unsatisfactory: lower values indicate a greater degree of satisfaction 
striking: first, the women questioned were more satisfied with the information they received about the actual process of Caesarean section than they were with the information they were given about the post-operative consequences. It appears that while counselling about Caesarean section for pregnant women deals with the technical aspects of the operation, it does not cover the post-operative aspects sufficiently, so that the women are left with the impression that the communication about risk is inadequate. Many women provided comments on their experience of a Caesarean section birth. Many of these comments suggest that the risks of a section are played down and that other problems, such as scar pain and the resulting difficulties experienced in caring for the newborn baby and problems with breastfeeding, are simply not dealt with (Lutz and Kolip 2006). This is illustrated by the following two quotes:

I feel that women should be given more information as to how they might be feeling after the birth. It should be made perfectly clear that a Caesarean section is in no way a pain-free option for giving birth! In fact, quite the opposite, the pain begins at a time when you would far rather be looking after the baby. In my case, that was not made clear and I was not given a true picture of what it would be like (Lutz and Kolip 2006, p 94).

All women should be given a much clearer picture of the type of post-operative problems they may find themselves having to deal with (problems breastfeeding, pain, feeling of numbness, scarring). The public perception is one of a routine operation, but it is in actual fact major abdominal surgery for the woman (Lutz and Kolip 2006, p 114).

Second, it is noticeable that approximately $20 \%$ of the women questioned said that their maternity care had not included a midwife. This is all the more astounding because women in Germany have a choice as to who will care for them during their pregnancy: their gynaecologist, a midwife, or a combination of the two. Those women in our study that chose a midwife as maternity care provider during pregnancy (alone or in combination with a gynaecologist) are mostly satisfied. In their freely worded comments, the women in our study claimed that midwives took more time with them compared to doctors and, when asked questions, offered a broader point of view beyond just the medical, which also embraced relevant psychosocial aspects of maternity care. Two quotes can also be used to illustrate this point of view:

The doctor is abrupt and the waiting room is always full. Many doctors only seem to consider the birth from a medical point of view. Midwives are often also able to see things from another angle, one that is more focussed on mother and child (Lutz and Kolip 2006, p 129).

It should be made public knowledge that midwives begin their maternity care of expectant mothers long before the actual birth. The experience and knowledge of the midwives is reassuring and enables them to answer specific questions (Lutz and Kolip 2006, p 129).

It can be assumed that the maternity care concept offered by midwives is far more women oriented and emphasizes aspects of empowerment and salutogenesis. This offers some starting points for improving the maternity care of expectant mothers. For example, health insurance funds could make women more aware of the option to receive maternity care by midwives. However, for this purpose, it is also necessary to dismantle the structural barriers that hamper an interprofessional cooperation between midwives and local gynaecologists.

The study also suggests that women use a broad range of different sources of information to prepare themselves for birth. The doctor who provides the woman's maternity care is the main source of information, as well as the midwife and books. This, again, underlines the important role played by medical professionals in the maternity care of women and the great need to be aware of the risk of medicalization of this phase in women's lives. The highest satisfaction grade was awarded to personal contact with professionals, presumably because this contact provides women with the opportunity to ask personal questions. Our study did not show any distinctions in levels of education as far as the use of sources of information was concerned. These sources of information were used regardless of the educational status of the women - a result already indicated in other studies (e.g. Graham et al. 1999). The study also showed no differences with regard to satisfaction with the information provided by the various sources, with one exception. Satisfaction with the use of the Internet was the only area to indicate differences; the tendency was for women who were better educated to be more satisfied. There may be several reasons for this: women who are better educated could use the Internet more, know more selective search strategies and may be more confident about their ability to assess information provided by the Internet.

We had assumed that the differences in education would be more distinct and that there would be a greater need for information among women who were less educated, that they would feel less involved in the decision-making and would be less satisfied with the information given. However, the educational level of the women in our study had little effect on the use of or satisfaction with information in the context of maternity care. This corresponds with other studies on shared decision-making in the 
context of other service provisions, which indicate only slight or no connections between levels of education/social class and behaviour when seeking information or preference for shared decision-making (Ende et al. 1989; Beisecker and Beisecker 1990; Wensing et al. 2002). It is even possible to indicate a reverse behavioural pattern, which is not significant, however: women with higher levels of education tend to feel they have not been as well informed about the process and post-operative consequences of a Caesarean section. More frequently, they also have questions that have not been answered. This paradox may be explained by the fact that during their maternity care better educated women have more questions that need to be answered. It must be noted that, even though some women wanted more information, the information they actually did receive may have been satisfactory. Furthermore, this study suggests that professionals responsible for providing maternity care should be aware of the various information requirements (Freda et al. 1993).

Some limitations of the study need to be mentioned. The study only includes women who were insured with the Gmünder Ersatzkasse (GEK). With 1.5 million members this is the fourth largest Germany-wide health insurance fund and was therefore of sufficient size for the purposes of this investigation. The results of numerous investigations with GEK data lead one to conclude that, based on the GEK population within the same gender and age groups, the results are generally transferable to members of other statutory health insurance funds (as the comparison to perinatal statistics show, Niedersächsische Perinatalstatistik 2004) but not to people who have private health insurance (approximately $10 \%$ of all individuals in Germany) (Glaeske and Janhsen 2008). Despite this limitation, the study provides valuable information for advising and supporting pregnant women and women in labour.

\section{Conclusions}

Even if the women questioned are largely of the opinion that their information requirements were satisfied during maternity care and they are also happy with their decision to have had a Caesarean section, our study revealed two very clear shortcomings in maternity care. First, women are not sufficiently well informed about the post-operative consequences of a Caesarean section. In the case of elective Caesarean sections in particular, it is essential to provide women with information, not only about the process itself, but also about the post-operative consequences. In the case of relative indications, risks and benefits must be carefully weighed against each other. If women are to be actively integrated into shared/informed decision-making, they require professional advice on the short-, medium- and long-term consequences of the operation. The second very clear shortcoming was the fact that midwives are not always involved in maternity care. This was indicated by the fact that one in five primiparae stated that there was no midwife involvement at all during pregnancy. Even when it becomes apparent in the early stages of pregnancy that a woman will have an at-risk birth and a Caesarean section be necessary, a midwife should be involved in the maternity care in order to provide space and opportunity to provide care that extends beyond just the medical aspects. It is therefore essential to strengthen the structure of the work of midwives in Germany.

Acknowledgements The study was funded by the Gmünder Ersatzkasse, a German health insurance fund.

Conflict of interest The authors confirm that there are no relevant associations that might pose a conflict of interest.

\section{References}

American College of Obstetricians and Gynecologists (2004) Ethics in obstetrics and gynecology, 2nd edn. American College of Obstetricians and Gynecologists, Washington DC

Beisecker AE, Beisecker TD (1990) Patient information-seeking behaviors when communicating with doctors. Med Care 28:19-28

BQS Bundesgeschäftsstelle Qualitätssicherung (2008) BQS Auswertung 2007 Geburtshilfe. http://www.bqs-outcome.de/2007/ergeb nisse/leistungsbereiche/geburtshilfe/buaw. Accessed 22 Jul 2008

Charles C, Whelan T, Gafni A (1999) What do we mean by partnership in making decisions about treatment? BMJ 319:780-782

Denk CE, Kruse LL, Jain NJ (2006) Surveillance of caesarean section deliveries, New Jersey, 1999-2004. Birth 33:203-209

Ende J, Kazis L, Ash A, Moskowitz MA (1989) Measuring patients' desire for autonomy: decision making and information-seeking preferences among medical patients. J Gen Intern Med 4:23-30

Enkin M, Keirse MJNC, Neilson J et al (2000) A guide to effective care in pregnancy and childbirth, 3rd edn. Oxford University Press, Oxford

Fleissig A (1993) Are women given enough information by staff during labour and delivery? Midwifery 9:70-75

Freda CM, Andersen HF, Damus K, Merkatz IR (1993) What pregnant women want to know: a comparison of client and provider perceptions. J Obstet Gynecol Neonatal Nurs 22:237-244

Glaeske G, Janhsen K (2008) Der GEK-Arzneimittelreport 2008. Asgard, St. Augustin

Graham WJ, Hundley V, McCheney AL, Hall MH, Gurney E, Milne J (1999) An investigation of women's involvement in the decision to deliver by caesarean section. Br J Obstet Gynaecol 106:213-220

Horey D, Weaver J, Russel H (2004) Information for pregnant women about cesarean birth. Cochrane Database Syst Rev 2004, Issue 1. Art. No. CD003858. doi:10.1002/14651858.CD003858.pub2

Sagadyleslie M (2004) Counseling women about elective cesarean section. J Midwifery Womens Health 49:155-159

Liu S, Liston RM, Joseph KS, Heaman M, Sauve R, Kramer MS, Maternal Health Study Group of the Canadian Perinatal Surveillance System (2007) Maternal mortality and severe morbidity associated with low-risk planned cesarean delivery versus planned vaginal delivery at term. CMAJ 176:455-460 
Lutz U, Kolip P (2006) Die GEK-Kaiserschnittstudie. Schriftenreihe zur Gesundheitsanalyse, Band 42. Asgard, St. Augustin

McFarlin BL (2004) Elective cesarean birth: issues and ethics of an informed decision. J Midwifery Womens Health 49:421-429

Menacker F, Declerq E, Macdorman MF (2006) Cesarean delivery: background, trends, and epidemiology. Semin Perinatol 30:235-241

Mould TAJ, Chong S, Spencer JAD, Gallivan S (1996) Women's involvement with the decision preceding their caesarean section and their degree of satisfaction. Br J Obstet Gynaecol 103:1074-1077

NICE - National Institute for Clinical Excellence 2004 Caesarean section. Clinical Guideline 13. http://www.nice.org.uk/page. aspx?o=113192. Accessed $20 \mathrm{Jul} 2008$

Niedersächsische Perinatalstatistik, Geburtskohorte 2004. Available at: http://www.zq-aekn.de

O'Cathain A, Thomas K, Walters SJ, Nicholl J, Kirkham M (2002) Women's perceptions of informed choice in maternity care. Midwifery 18:136-144
OECD Health Data 2006. http://www.gbe-bund.de/ -> Kaiserschnitt. Accessed 27 Jul 2008

Scheibler F, Janßen C, Pfaff H (2003) Shared-decision making: Ein Überblicksartikel über die internationale Forschungsliteratur. Soz Präventivmed 48:11-23

Stapleton H, Kirkham M, Thomas G (2002) Qualitative study of evidence based leaflets in maternity care. BMJ 324:639

Tollånes MC, Thompson JM, Daltveit AK, Irgens LM (2007) Cesarean section and maternal education; secular trends in Norway, 1967-2004. Acta Obstet Gynecol Scand 86:840-888

Turnbull DA, Wilkinson C, Yaser A, Carty V, Svigos JM, Robinson JS (1999) Women's role and satisfaction in the decision to have a caesarean section. Med J Aust 170:580-583

Wensing M, Elwyn G, Edwards A, Vingerhoets E, Grol R (2002) Deconstructing patient centred communication and uncovering shared decision making: an observational study. BMC Med Inform Decis Mak 2:2 